\title{
Disseminated Cryptococcosis in an Immunocompetent Child
}

\author{
Bhawna Bhutoria JAIN, Debdas BOSE, Rajat MONDAL, Sarbani CHATTOPADHYAY
}

Department of Pathology, Medical College, Kolkata, WEST BENGAL, INDIA

\begin{abstract}
A case of disseminated cryptococcus infection in an immunocompetent host is described. The present case attests to the importance of using a cautious approach for the diagnosis of granulomatous lymphadenitis. The patient was initially misdiagnosed and treated as disseminated tuberculosis. Later the patient developed visual loss and skin lesions. Periodic Acid Schiff stained sections of lymph node biopsy and cerebrospinal fluid culture established the diagnosis.
\end{abstract}

Key Words: Cryptococcus, Disseminated, Skin diseases

\section{INTRODUCTION}

Cryptococcus neoformans is capsulated yeast commonly found in soil contaminated by bird faeces throughout the world (1). Infection is principally caused by two species in the Cryptococcus genus, namely Cryptococcus neoformans var. neoformans and Cryptococcus neoformans var. gattii. Cryptococcus neoformans is found worldwide, commonly in pigeon excreta in soil, and it causes disease in immunecompromised hosts. Cryptococcus neoformans var. gattii. has recently been recognised as a distinct emerging pathogen causing disease in humans and animals. It is found predominantly in tropical and subtropical regions and causes disease in immunocompetent individuals (2). In addition to HIV infection, immunosuppressive medications, solid-organ transplantation, chronic organ failure, hematologic malignancy, chronic lung disease, and rheumatologic disorders can also predispose individuals to this infection (3).

Reported cases of cryptococcal infections in an immunocompetent host have primarily included pulmonary manifestations and cutaneous lesions (4). In this case report, we describe a case of disseminated cryptococcosis in an immune competent child that was initially misdiagnosed as tuberculosis and later on led to characteristic skin lesions.

\section{CASE REPORT}

A 7-year-old boy suffered from intermittent high grade fever, severe headache followed by vomiting and irritability for six months. Physical examination revealed splenomegaly with right sided cervical lymphadenopathy. Bilateral chest crepitations were noted on auscultation.

(Turk Patoloji Derg 2017, 33:77-80)

Received : 21.11.2013 Accepted : 10.12.2013
Hematological investigations done revealed total white blood cell count-23200, eosinophilic leucocyte percentage $54 \%$, haemoglobin- $7.4 \mathrm{~g} / \mathrm{dl}$, and erythrocyte sedimentation rate: $58 \mathrm{~mm} /$ hour. Chest $\mathrm{x}$-ray showed bilateral diffuse infiltrates. Sputum for acid fast bacilli (AFB) was negative. Blood malaria parasite was negative, Bactec blood culture showed no growth. Urine culture did not show any growth after 48 hours. Stool examination revealed red blood cells and test for occult blood was positive.

The patient was nonreactive for HIV 1 and HIV 2 antibodies. Widal test and serum anti-nuclear antigen was negative. Liver function tests were within normal limits. C-reactive protein was $215.6 \mathrm{mg} / \mathrm{L}$.

Ultrasonography of the abdomen showed enlarged liver with heterogeneous parenchyma and retroperitoneal lymph nodes. Bone marrow aspiration was reported as myeloid hyperplasia with increase in eosinophilic leucocyte count. Cerebro-spinal fluid (CSF) analysis failed to demonstrate any organism. CSF adenosine deaminase (ADA) level was within reference range. The blood culture and Widal test were also negative. Lymph node FNAC revealed granulomas. The patient was put on anti-tubercular drugs (ATD). However, the fever persisted. Then the patient suddenly developed bilateral loss of vision. Ophthalmoscope examination showed bilateral choroiditis, tuberculomas and papillitis. Magnetic resonance imaging (MRI) brain showed mild prominent cortical sulci with dilation of lateral ventricles suggestive of meningitis sequel. Biopsy of cervical lymph node demonstrated non-caseating epithelioid cell granulomas. The patient was advised to continue ATD.

Correspondence: Bhawna Bhutoria JAIN

Medical College, Department of Pathology, Kolkata,WEST BENGAL, INDIA

E-mail: bbhutoria@gmail.com Phone: +9433089319 
Afterwards the patient developed umbilicated papules over face and trunk (Figure 1A). Serum IgE level was $1175 \mathrm{IU} /$ $\mathrm{ml}$ (reference normal< $90 \mathrm{IU} / \mathrm{ml}$ ). As the fever persisted, the lymph node biopsy was sent to us for review. On careful examination of the granulomatous lesion, small fungal yeasts were demonstrated inside the macrophages and confirmed by PAS stain (Figure 2A-C). Skin biopsy done later (Figure 1B-D) also revealed ill-formed granulomas and yeast cells within macrophages. CSF fluid and blood sent for fungal culture (Figure 2D) to the School of Tropical medicine, which identified the organism as Cryptococcus neoformans. The patient was treated with Amphotericin-B followed by Fluconazole and is in remission at present.

\section{DISCUSSION}

The purpose of presenting this case is to highlight the importance of careful evaluation of granulomatous lymphadenitis particularly in tuberculous endemic regions.
We also discuss how presenting features of such uncommon infections mimic tuberculosis.

Cryptococcus is a soil saprophyte and is abundant in the faeces of pigeons and other birds. It is basidiomycetous yeast that exists in the environment in the sexual form and produces hyphae with terminal basidiospores (chains of unbudded yeast). When the 3 micron basidiospores break off they become aerosolized and may be inhaled into the alveoli. An infection is asymptomatic in most persons, but the organism may enter the circulation and survive in vivo in a haploid, asexual state, leading to disseminated disease in persons with severe cell-mediated immunodeficiency. In humans, cryptococci may survive because of a polysaccharide capsule that allows them to evade phagocytosis. In addition, a phenol oxidase enzyme uses catecholamine as substrate to produce melanin, which accumulates in the cell wall, and synthesis of catecholamine
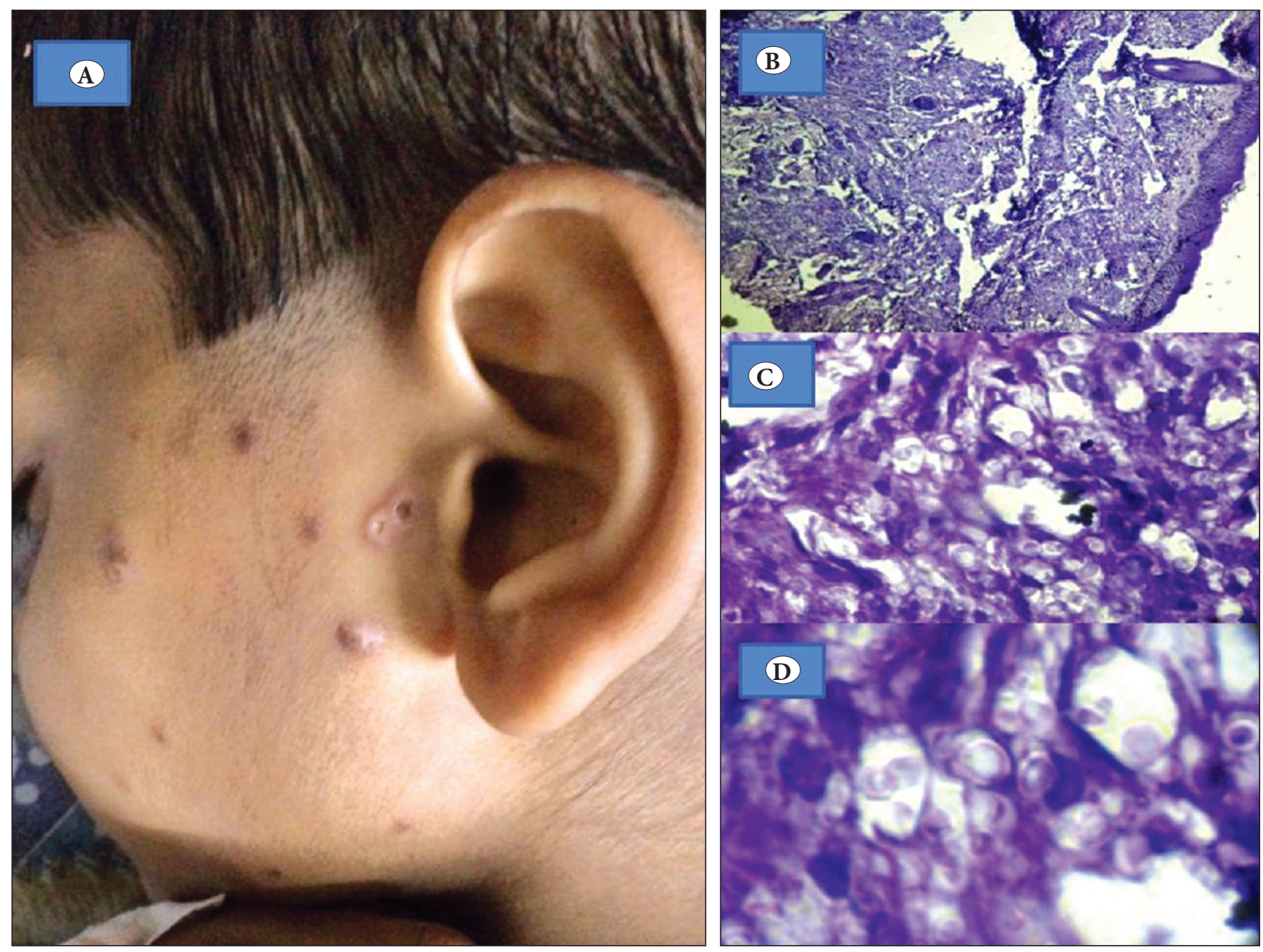

Figure 1: A) Skin papules with central umbilication. Microphotograph of skin lesion. B) (H\&E; x40), C) (H\&E; x400), D) (H\&E; x1000). 

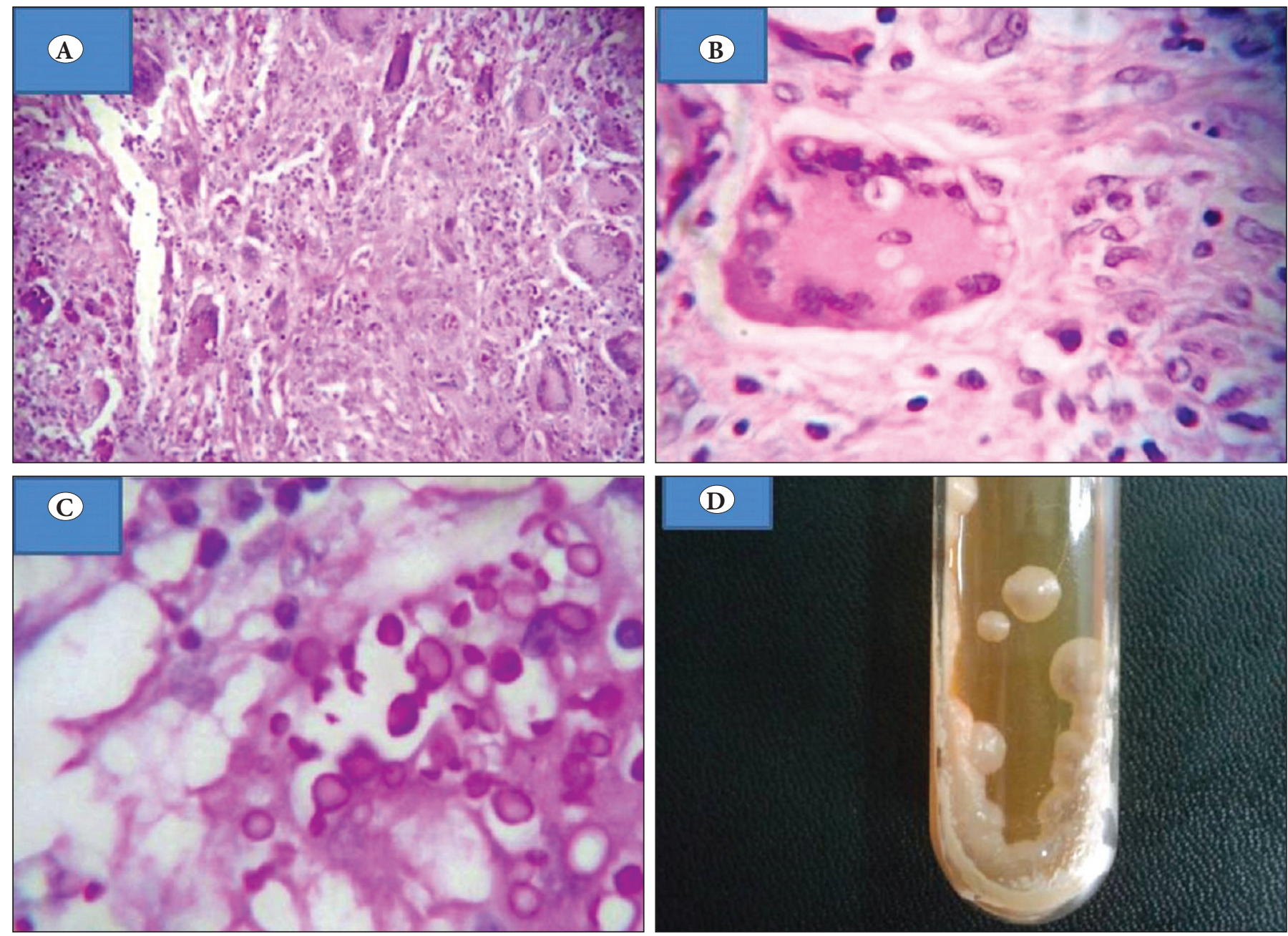

Figure 2: Microphotograph of PAS stained sections of lymph node. A) Non-caseating granulomas in low power view (PAS, x40). B) A giant cell in high power view showing intracellular cryptococcus surrounded by clear halo (PAS, $\mathrm{x} 400$ ). C) Oil immersion view showing yeast cells with narrow based budding (PAS, x1000). D) Culture showing cream-coloured smooth, mucoid colonies (SDA).

for neurotransmitters may predispose to involvement of the central nervous stem (5). However, disseminated cryptococcal infection is uncommon and almost always occurs in HIV-infected patients (4).

Disseminated cryptococcosis is defined by (1) a positive culture from at least two different sites or (2) a positive blood culture (6). In the present case organisms were cultured from blood and CSF.

Clinical presentation of disseminated cryptococcosis is variable and depends on the organ systems involved (7). Central nervous system involvement is the most common manifestation of disseminated disease (6). Common presenting symptoms include headache, fever, and malaise. Classic meningitis signs, such as nuchal rigidity, are absent in $75 \%$ of cases (8). Our case also presented with fever, headache and vomiting. Neck rigidity was absent.
In tuberculous endemic regions, cryptococcosis may be misdiagnosed as tuberculous infection (9). Visual changes have been reported, such as the field defects, as well as new onset seizure activity (10). Secondary involvement of skin is apparent in about $10 \%$ to $20 \%$ of immune-compromised patients with cryptococcosis (11). The skin lesions typically appear as pedunculated, dome-shaped papules with an umbilicated centre (12). Similar findings were noted in our patient too.

Philip K. et al. have described similar case as ours with generalised lymphadenopathy, hepatosplenomegaly, skin lesions and miliary mottling of chest radiograph (13). Cryptococcosis among immunocompetent patients tended to be associated with lower rates of fungaemia, when compared to non-HIV-infected patients with predisposing factors (8). 
Microscopically, C. neoformans organisms are pale narrowbased budding yeasts that average 2 to 7 microns in size with a prominent surrounding capsule. The yeast cells appear pale blue and ovoid while the capsule is round and clear with routine hematoxylin-eosin stained tissue sections or on Papanicolaou stained cytological material. With the capsule, the organisms are 5 to 20 microns. The accompanying scanty inflammation contains a few small, scattered lymphocytes or macrophages with phagocytized organisms (14). The cellular pleomorphism of cryptococci, larger cell size, and lack of pseudohyphae help to distinguish it from Candida. The football-shaped C. neoformans yeasts are much larger than the small round cells of $H$. capsulatum organisms (15).

To conclude one should apply a cautious approach towards the diagnosis and treatment of granulomatous lymphadenitis and should not be biased towards TB. Caseation should be looked for and if absent, other causes of granulomas to be considered. Absence of immunosuppression should not be a reason to exclude cryptococcosis from the differential diagnosis.

\section{REFERENCES}

1. Gaskill T, Payne D, Brigman B. Cryptococcal abscess imitating a soft-tissue sarcoma in an immunocompetent host: A case report. J Bone Joint Surg Am. 2010;92:1890-3.

2. Mitha M, Naicker P, Mahida P. Disseminated Cryptococcosis in an HIV-negative patient in South Africa: The elusive differential diagnosis. J Infect Dev Ctries. 2010;4:526-9.

3. Pappas PG, Perfect JR, Cloud GA, Larsen RA, Pankey GA, Lancaster DJ, Henderson H, Kauffman CA, Haas DW, Saccente M, Hamill RJ, Melissa MS, Warren RM, Dismukes WE. Cryptococcosis in human immunodeficiency virus-negative patients in the era of effective azole therapy. Clin Infect Dis. 2001;33:690-9.
4. Suchitha S, Sheeladevi CS, Sunila R, and Manjunath GV. Disseminated Cryptococcosis in an immunocompetent patient: A case report. Case Rep Pathol. 2012;2012:652351.

5. Warkentien T, Crum-Cianflone NF. An update on Cryptococcus among HIV-infected patients. Int J STD AIDS. 2010;21:679-84.

6. Chuang YM, Ho YC, Chang HT, Yu CJ, Yang PC, Hsueh PR. Disseminated cryptococcosis in HIV-uninfected patients. Eur J Clin Microbiol Infect Dis. 2008;27:307-10.

7. Kokturk N, Ekim N, Kervan F, Arman D, Memis L, Caglar K, Kalkanci A, Demircan S, Kurul C, Akyurek N. Disseminated cryptococcosis in a human immunodeficiency virus-negative patient: A case report. Mycoses. 2005;48:270-4.

8. Lui G, Lee N, Ip M, Choi KW, Tso YK, Lam E, Chau S, Lai R, Cockram CS. Cryptococcosis in apparently immunocompetent patients. QJM. 2006;99:143-51.

9. Patro S N, Kesavadas C, Thomas B, Kapilamoorthy T R, Gupta AK. Uncommon presentation of intracranial cryptococcal infection mimicking tuberculous infection in two immunocompetent patients. Singapore Med J. 2009;50:e133-7.

10. Mwanza JC, Nyamabo LK, Tylleskar T, Plant GT. Neuroophthalmological disorders in HIV infected subjects with neurological manifestations. Br J Ophthalmol. 2004;88:1455-9.

11. Tilak R, Prakash P, Nigam C, Tilak V, Gambhir IS, A K Gulati AK. Cryptococcal meningitis with an antecedent cutaneous cryptococcal lesion. Dermatology Online Journal. 2009;15:12.

12. Probst C, Pongratz G, Capellino S, Szeimies RM, Schölmerich J, Fleck M, Salzberger B, Ehrenstein B. Cryptococcosis mimicking cutaneous cellulitis in a patient suffering from rheumatoid arthritis. BMC Infect Dis. 2010;10:239.

13. Philip KJ, Kaur R, Sangeetha M, Masih K, Singh N, Mani A. Disseminated cryptococcosis presenting with generalized lymphadenopathy. J Cytol. 2012;29:200-2.

14. Edward C. Klatt. Pathology of AIDS. available on http://library. med.utah.edu/WebPath/AIDS2013.PDF. Accessed on 30/09/2013

15. Shibuya K, Coulson WF, Wollman JS, Wakayama M, Ando T, Oharaseki T, Takahashi K, Naoe S. Histopathology of cryptococcosis and other fungal infection in patients with acquired immunodeficiency syndrome. Int J Infect Dis. 2001;5: 78-85. 